\title{
Biopoder e normalização da infância: Apontamentos sobre a instrumentalização do lúdico
}

\author{
Biopower and education of children: Notes on the instrumentalization of play
}

Joc̃o Paulo Pereira Barros ${ }^{[a]}$, Veriana de Fátima Rodrigues Colaço ${ }^{[b]}$

${ }^{[a]}$ Doutorando em Educação Brasileira na Universidade Federal do Ceará (UFC), Fortaleza, CE - Brasil, e-mail: jppbarros@yahoo.com.br

${ }^{[b]}$ Doutora em Educação pela Universidade Federal do Rio Grande do Sul (UFRGS), professora do Programa de Pós-Graduação em Psicologia e do Programa de Pós-Graduação em Educação Brasileira da Universidade Federal do Ceará (UFC), Fortaleza, CE - Brasil,

e-mail: verianac@uol.com.br

Recebido: 01/03/2012

Received: 03/01/2012

Aprovado: 22/03/2012

Approved: 03/22/2012

\section{Resumo}

O presente artigo tem por objetivo discutir como as relações entre biopoder e produção de subjetividades infantis apontam pistas sobre a instrumentalização da atividade lúdica na educação infantil. Para tanto, são estabelecidos diálogos com teóricos de vertentes psicológicas e socioantropológicas que tratam da brincadeira, mas fundamentalmente com Foucault e autores que o tomam como referência para problematizar assuntos relativos à infância. Em um primeiro momento, o texto aborda o biopoder na perspectiva foucaultiana, ressaltando sua relação com a construção histórico-social da infância e sua articulação com o campo da educação. Já num segundo momento, o texto levanta questões conceituais acerca da atividade lúdica e suas tensões no âmbito da escola a partir das reflexões socioantropológicas de Gilles Brougère e de considerações oriundas do campo da psicologia, com destaque para Lev Seminiovitch Vygotsky, Daniil Elkonin e Henry Wallon. Em seguida, reflete-se sobre dispositivos de normalização da infância a partir da apropriação da atividade lúdica como instrumento pedagógico no contexto escolar. 0 ensaio conclui que tal apropriação se articula intimamente com a própria invenção e institucionalização da infância na Modernidade e com o aprimoramento de novas modalidades de poder, como a disciplina e a biopolítica, as quais incidem, de modo simultâneo e complementar, nos indivíduos e nas populações, respectivamente.

Palavras-chave: Biopoder. Educação. Infância. Lúdico.

\section{Abstract}

This paper aims to discuss how the relationship between biopower, education and children's production of subjectivity clues point the instrumentalization of play activity in early childhood education. To that end, establishing a dialogue with theoretical anthropological and social psychological aspects dealing with the joke, but mainly with Foucault and the authors make reference to complicate matters relating to children. At first, the text discusses biopower in Foucault's perspective, emphasizing its relation to historical and social construction of childhood and its relationship with the field of education. Already in a second time, the text raises conceptual questions about the play activity and their tensions within the school, from social anthropological reflections by Brougère Gilles and considerations arising from the field of psychology, especially 
Lev Seminiovitch Vygotsky, Daniil Elkonin and Henry Wallon. Then it was discussed devices standardization of childhood from the appropriation of the play activity as an educational tool in the school context. The essay concludes that such appropriation is intimately related to the invention and institutionalization of childhood in Modernity and the improvement of new modalities of power, such as discipline and biopolitics, which relate, in a simultaneous and complementary, in individuals and populations, respectively.

Keywords: Biopower. Education. Childhood. Playful.

\section{Introdução}

0 propósito deste artigo é discutir de que maneira as relações entre biopoder e produção de subjetividades infantis fornecem pistas acerca das crescentes tentativas de controle e instrumentalização da atividade lúdica no contexto da educação infantil. Tal objetivo se viabilizará a partir de diálogos com teóricos de matrizes psicológicas e socioantropológicas que versam sobre brincadeira, mas, sobretudo, com a perspectiva pós-estruturalista de Foucault e com autores que a tomam como referência para pensar questões relativas à infância.

Não obstante, o tratamento desse tema requer a explicitação de dois pressupostos que serão considerados ao longo do texto.

0 primeiro desses pressupostos é o de que a Modernidade se configurou num palco de transformações das percepções e categorizações sobre os sujeitos. Nesse contexto, têm-se a fabricação/invenção da infância (Bujes, 2002). A partir desse viés, a infância tem sido cada vez mais utilizada como uma noção heurística, capaz de gerar problematizações sobre a própria sociedade. Mais especificamente, a noção de infância nos permite pensar sobre seu processo de institucionalização/escolarização e sobre o especial destaque à atividade lúdica daí decorrente (Pagni, 2010; Sarmento, 2004).

Por seu turno, o segundo pressuposto é o de que os nexos entre biopoder e educação, segundo Gadelha (2009, p. 15), não são um fato óbvio e devidamente assinalado na obra de Foucault, mas sim algo a ser traçado a partir dela:

De fato, objetivamente falando, ele [Foucault] não tomou a educação - como o fez, por exemplo, com a medicina social (a medicalização da vida, a instalação de um dispositivo da sexualidade), a polícia, a previdência social e o racismo biológico de Estado, dentre outros - como um dos mecanismos estratégicos privilegiados para o exercício de biopoderes e de biopolíticas nas sociedades ocidentais modernas.

Com base nesses pressupostos, vislumbramos a possibilidade de responder ao seguinte questionamento: como as relações entre biopoder e a produção da subjetividade infantil nos permitem compreender a apropriação da brincadeira e do jogo no cotidiano escolar?

Para tanto, o artigo encontra-se organizado em três seções. Na primeira, apresentaremos apontamentos foucaultianos sobre o biopoder, destacando sua relação com a construção histórico-social da infância e sua articulação com o campo da educação a partir da Modernidade. Na segunda seção, levantaremos questões a respeito do jogo e da brincadeira, tomando como referência desde as reflexões socioantropológicas de Gilles Brougère até as considerações de autores da matriz histórico-cultural da Psicologia, como Lev Seminiovitch Vygotsky e Daniil Elkonin. Por último, na terceira seção, traremos discussões sobre dispositivos de normalização da infância que se articulam às tentativas de pedagogização da atividade lúdica no contexto escolar.

\section{Biopoder, construção da infância e as novas experiências educativas}

Segundo Gadelha (2009), antes de Foucault, as problemáticas relativas ao poder vinham sendo tratadas sob uma perspectiva jurídico-política ou jurídico-filosófica. Foi o pensador francês quem, de maneira efetiva, abordou o assunto sob um viés histórico-político ou histórico-filosófico, imanentista e microfísico. Na perspectiva de Foucault (1979, 2005), o poder é compreendido como relacional, estratégico, acentrado, exercendo-se de formas 
diversas, em diferentes níveis sociais, e não como uma propriedade identificada necessariamente com o Estado e/ou deduzida da Economia. Assim, o poder não só coage, reprime e proíbe, mas também é constitutivo, participando ativamente, por exemplo, da produção de subjetividades. Nas palavras do próprio Foucault (2010, p. 288),

ele [o poder] não é em si mesmo uma violência que poderia se esconder ou um consentimento que se reconduziria. É um conjunto de ações sobre ações possíveis: ele opera sobre o campo de possibilidades em que se inscreve o comportamento dos sujeitos ativos; ele incita, induz, desvia, facilita ou dificulta, amplia ou limita, torna mais ou menos provável; no limite, coage ou impede absolutamente, mas é sempre um modo de agir sobre um ou vários sujeitos ativos, e o quanto eles agem ou são suscetíveis de agir. Uma ação sobre ações.

Em meio à tematização do poder, Foucault (1999) assinala que as tecnologias políticas que exerciam controle sobre os corpos e que condicionavam o funcionamento das sociedades ocidentais modernas - bem como de suas instituições, dentre elas a escola - transformaram-se significativamente no século XVIII. Isso porque, a partir de então, passou-se a estar às voltas com uma modalidade nova de poder, a qual, diferentemente das anteriores, encarregava-se da vida, e não da morte: o biopoder.

Para Foucault (1999, p. 302), o biopoder é aquele que "se incumbiu da vida em geral, com o pólo do corpo e o pólo da população". O biopoder, então, possui dois eixos - o poder disciplinar e a biopolítica - os quais incidem, respectiva e articuladamente, sobre o indivíduo e sobre a coletividade. Desse modo, Foucault (1999) aponta um dos fenômenos fundamentais do século XIX: o aparecimento de uma nova tecnologia de poder caracterizada por fazer viver e deixar morrer, diferentemente do poder soberano, que se alicerçava no direito de matar e se exercia a partir de mecanismos de castigo e tortura.

De acordo com tratamento dado por Foucault, o biopoder teria duas dimensões, as quais devem ser vistas como complementares, e não como dicotômicas: o poder disciplinar e a biopolítica.

0 poder disciplinar se baseia no panóptico, agiria no indivíduo, na condição de corpo-organismo, como uma anatomia política do detalhe. Seu objetivo seria o "adestramento", a produção de corpos dóceis, úteis e produtivos, treinando o corpo, reforçando suas aptidões e extraindo o máximo de suas forças por meio de um controle minucioso do tempo e do espaço, materializado a partir de práticas de vigilância hierárquica, exames e sanções normatizadoras (Foucault, 2005). Já a biopolítica agiria na coletividade, na condição de corpo-espécie, tendo como objeto os modos de vida da população. Seu objetivo seria o estabelecimento de mecanismos de regulação social, para o qual é utilizada uma gama de saberes criados a partir da Modernidade, como a Estatística, a Saúde Pública e os próprios saberes $p s i$.

A propósito da biopolítica, Foucault começou a desenvolver sua discussão em 1974, frisando de que modo a medicina social se configurou como uma estratégia de regulação da vida da população no século XIX. Naquele contexto, segundo Foucault (1979), a biopolítica vinculava-se historicamente à constituição e ao fortalecimento do Estado nacional, bem como à afirmação da burguesia e à formação de um dispositivo médico e jurídico ligado à normalização social.

Entre 1977 e 1979, o autor formula suas últimas discussões sobre biopolítica, em dois cursos ministrados no Collège de France: Segurança, território, população (Foucault, 2008a) e Nascimento da biopolítica (Foucault, 2008b). Esses cursos dão novos e mais complexos contornos à discussão: em ambos, é abordada a questão da governamentalidade.

Segundo Foucault (2008a, p. 49), a governamentalidade diz respeito a uma sequência de operações estabelecidas no "contato entre as tecnologias de dominação dos outros e as voltadas para o eu", atuando, portanto, simultaneamente, na regulação das condições de vida da população e da existência dos indivíduos. Vale destacar que tais questões são de suma pertinência para o campo da educação, especialmente por suscitar questionamentos sobre seu papel na contemporaneidade, em específico sobre a institucionalização da educação escolar infantil e sobre a crescente tentativa de utilização da atividade lúdica como "instrumento" para a aprendizagem na escola.

E o que esse contexto indica sobre a construção da infância a partir da Modernidade? Para Isabel Bujes (2002, p. 32), é possível, a partir das reflexões de Foucault, estabelecer relações entre a "invenção do moderno sentimento de infância e o afã de governo das populações infantis". Nesse ponto, cabe a ressalva de que a noção foucaultiana de "governo" trata-o como um modo de dirigir a conduta alheia, estruturando-lhe um campo de ação. Segundo ressalta Foucault (1999), o biopoder opera segregando 
e hierarquizando. Assim é que Bujes (2002) destaca pelo menos duas repercussões desses jogos de poder no tocante à invenção da infância.

A primeira repercussão diz respeito à separação entre os mundos do adulto e da criança, o que resultará numa representação adultocêntrica da criança. Tal representação, por sua vez, justificará a intervenção e o governo da infância, abrindo espaço para novas experiências educativas. É por meio dessas mudanças e das novas configurações sociofamiliares que se constituem e se sedimentam, pois, as instituições educacionais modernas encarregadas das pequenas crianças, a partir da segunda metade do século XVIII.

Para Bujes (2002, p. 36),

são essas pressões a favor da vida e interessadas no seu governo que explicam o afã da sociedade em proteger/ regular as suas crianças, no quadro sociopolítico que se delineia na Era Moderna, com o processo de secularização das instituições sociais. A educação da infância se insere, pois, nesse conjunto de tecnologias políticas que vão investir na regulação das populações, através de processos de controle e de normalização.

Já a segunda repercussão, intimamente articulada à primeira, corresponde à consolidação dos saberes pedagógicos a partir desse novo cenário, fruto de uma crescente "vontade de saber" sobre a infância, de forma a balizar uma regulação mais eficaz sobre as crianças, mediante práticas educativas a elas destinadas. Portanto, fica claro que articuladamente ao biopoder produzem-se saberes e sujeitos, já que

as tecnologias aplicadas ao corpo permitem a extração de saberes sobre os sujeitos, saberes que, ao serem devolvidos aos sujeitos, o constituem como indivíduo, constroem o seu eu. Mas essas tecnologias, ao serem admitidas no campo do saber, produzem um disciplinamento dos saberes que é a própria condição de possibilidade de formação das ciências (Bujes, 2002, p. 37).

Nessa direção, tomando como referência as reflexões foucaultianas sobre o sujeito e o poder, podemos arrematar que o biopoder, quer em sua dimensão disciplinar, quer em sua dimensão biopolítica, está intrincado ao processo de pedagogização da infância.

No bojo do projeto educacional moderno, cujo projeto civilizador implica a individualização do sujeito, fixando, por exemplo, um conceito de infância, requer-se, pois, a criação de políticas sociais para esse segmento, como a educação infantil institucionalizada
(Bujes, 2002). Assim, doravante, a instituição escolar, por meio da pedagogização da infância, passa a contribuir sobremaneira no aprimoramento das táticas de governamentalidade e fabricação do sujeito moderno.

Por isso, Bujes (2002, p. 64) advoga que o campo pedagógico, muito mais do que um espaço meramente destinado a apenas favorecer o "florescimento" da criança, constitui-se como um campo de produção de subjetividade. Dessa forma é que a autora, seguindo a linha de pensamento de Foucault, chama atenção para o fato de que

a elaboração da narrativa da infância é um processo que se reforça pela instituição de práticas educativas e de cuidados que, por sua vez, têm efeitos que se remetem à elaboração de novos discursos sobre esta mesma infância, num efeito circular.

Ora, em meio a esse cenário de institucionalização da infância, a atividade lúdica, como atividade relacionada a esse segmento, passa a ser cada vez mais objeto de atenção. No contexto contemporâneo, aliás, o lúdico se faz cada vez mais presente em leis e planejamentos, impactando nas práticas levadas a cabo na educação infantil.

Essa preocupação comparece, por exemplo, nas Diretrizes Curriculares Nacionais para a Educação Infantil (DCNEI) de acordo com a resolução n. 1, de abril de 1999, que aponta a ludicidade como um dos fundamentos que orientam as práticas pedagógicas das instituições desse campo. A presença do lúdico nas escolas também se respalda no Referencial Curricular Nacional para a Educação Infantil/RCNEI (2001). Assim, "aos poucos, o lúdico está deixando de ser uma atividade encontrada apenas nos pátios das escolas e vem se integrando a muitas atividades sistemáticas realizadas dentro do contexto da sala de aula" (Pinto, 2010, p. 12).

No próximo tópico, então, traremos à tona algumas compreensões sobre brincadeira e jogo, tanto a partir de matrizes da Psicologia, quanto de vertentes socioantropológicas. Além disso, explicitaremos alguns pontos de tensão decorrentes desse "encontro" entre o lúdico e a educação da criança.

\section{Jogo e brincadeira: questões conceituais e tensões com o campo da educação}

A Perspectiva Histórico-Cultural figura como uma das principais realizações da Psicologia nas 
primeiras décadas do século XX. Vieram exatamente de seu fundador, o russo Lev Seminiovitch Vygotsky, e de seus legatários, como Leontiev, Luria e Elkonin, alguns dos mais fecundos estudos acerca de questões teóricas e metateóricas gerais relacionadas às investigações psicológicas. Nesse sentido, para Wertsch e Smolka (1995), a perspectiva histórico-cultural, a partir de sua ancoragem no materialismo histórico-dialético, apresenta três pontos principais: a constituição do psiquismo humano a partir da cultura, o caráter mediado de tal constituição, com destaque especial à mediação simbólica, e a utilização do método genético de investigação. Desse modo, vieram dessa matriz de pensamento proposições inovadoras no tocante à compreensão do desenvolvimento humano e de processos psicológicos nele envolvidos, como a memória mediada, o pensamento, a linguagem e a consciência, o que, até hoje, suscita possibilidades de diálogo, por exemplo, com o campo da educação. Sobre esses processos, Vygotsky (1995) os compreende como marca definidora do humano em distinção aos outros animais e os nomeia de "funções psicológicas superiores", cuja característica fundamental é o fato de serem mediadas, intencionais e reguladas pela vontade, portanto, constituídas na relação indissociável indivíduo-cultura.

Imbuído do objetivo de compreender o funcionamento psicológico humano, Vygotsky destinou atenção também à brincadeira e sua relação com o desenvolvimento infantil. Por sua vez, é Elkonin (1998) quem busca aprofundar as teorizações iniciadas por Vygotsky a esse respeito, em sua obra Psicologia do Jogo. Na discussão feita por Vygotsky (2007) e Elkonin (1998), não há distinção entre jogo e brincadeira. Percebe-se, na verdade, que os autores enfocam especificamente o jogo protagonizado ou jogo de papéis. Desse modo, é possível pontuar pelo menos duas justificativas intimamente articuladas para tal enfoque.

A primeira delas diz respeito ao fato de que, inspirado no método dialético de Karl Marx, Vygotsky (1995) adota um procedimento que ele mesmo chama de método inverso para o estudo das funções psicológicas superiores. De acordo com tal método, para se compreender a essência de qualquer fenômeno seria preciso estudar sua forma mais desenvolvida, refletindo assim a proposta sintetizada na metáfora de Marx (1978, p. 120) de que "a anatomia do homem é a chave da anatomia do macaco". Nesse sentido, o jogo protagonizado seria, para Vygotsky e Elkonin, a forma mais evoluída de brincadeira, permitindo o entendimento das formas anteriores e, ainda, da relação entre brincadeira e desenvolvimento psicológico da criança.

A segunda justificativa está vinculada ao fato de que a definição do método vygotskyano implica, por sua vez, entender seu plano de pesquisa, que era investigar como se constroem as funções psicológicas tipicamente humanas e sua concepção sobre a gênese do psiquismo. Com efeito, para Vygotsky (1995), haveria, no ser humano, uma síntese entre o desenvolvimento natural - e, portanto, uma história natural - e o desenvolvimento cultural, o que, nesse sentido, seria a história humana. Para o autor, as funções psíquicas podem superar as limitações orgânicas impostas pela evolução natural a partir do uso de ferramentas simbólicas, o qual traria, consequentemente, a diferenciação qualitativa entre funções naturais e culturais. Nesse sentido, a brincadeira seria tomada como atividade paradigmática dessa articulação.

Mas, afinal, como se caracterizaria a brincadeira a partir da matriz histórico-cultural adotada por Vygotsky e Elkonin? Primeiramente, a brincadeira se constituiria uma atividade da criança que pressupõe uma situação imaginária e um conjunto de regras de comportamento. Em segundo lugar, de acordo ainda com essa perspectiva, a brincadeira seria uma forma de atividade que atende a necessidades da criança, isto é, tratar-se-ia de uma situação na qual os desejos que não são possíveis de serem realizados imediatamente, por conta da condição da criança, como ser pai, mãe ou jogador(a) de futebol, podem ser realizados ao menos num plano imaginário. Portanto, para Vygotsky (2007), e também para Elkonin (1998), a brincadeira se caracterizaria por ser uma atividade eminentemente sociocultural, e não inata.

Esse posicionamento teórico dos autores russos os diferencia de uma série de vertentes psicológicas anteriores que, ancoradas num pensamento romântico ou etológico, operavam uma naturalização do brincar (Brougere, 1995, 1998). Desse modo, como atividade social que pressupõe regras e situação imaginária, a brincadeira evoluiria na criança no seguinte sentido: de atividades em que há uma situação imaginária às claras e regras ocultas para atividades com regras às claras e uma situação imaginária oculta (Vygotsky, 2007). Logo, de acordo com essa matriz de pensamento psicológico, a 
brincadeira teria um importante papel no desenvolvimento da criança.

A esse respeito, Vygotsky (2007) aponta que a criação de situações imaginárias seria a primeira manifestação da independência das restrições situacionais por parte da criança. Assim sendo, a brincadeira ajudaria a instaurar uma nova relação da criança com os significados e com os objetos, contribuindo para que ela aprenda a agir num âmbito eminentemente simbólico. Ademais, a criação de situações imaginárias mediante a brincadeira contribuiria para que houvesse um predomínio do significado diante dos objetos e da ação propriamente dita, bem como para o desenvolvimento do pensamento abstrato, fruto da articulação, num plano ontogenético, entre pensamento e linguagem (Vigotski, 2001). Dessa forma, a brincadeira possibilitaria, ainda, um maior controle da criança sobre sua própria conduta, já que contém regras às quais a criança deve atentar, uma apropriação paulatina de papéis e de regras sociais, assim como um campo de aprendizagens possíveis a partir da emergência de zonas de desenvolvimento proximais (ZDPs).

Por essa direção, podemos encontrar alguns pontos de semelhança entre as reflexões gestadas pela matriz histórico-cultural de Vygotsky e as reflexões de Henry Wallon a respeito do "brincar"1. Assim como em Vygotsky, não se observa em Wallon uma diferenciação entre jogo e brincadeira. Para o citado autor francês, a brincadeira seria um componente fundamental do desenvolvimento integral da criança, uma vez que, à semelhança do que ressalta Vygotsky, implica o aperfeiçoamento da função simbólica e a complexificação da relação com o meio. Portanto, para Wallon (2007), assim como para os autores da matriz histórico-cultural assinalados alhures, haveria uma relação ambígua entre brincadeira e realidade.

Isso se justifica porque, ao mesmo tempo em que se diferencia de uma atividade realista ou prática, o lugar e os meios da atividade lúdica estariam no mundo exterior. Nesse sentido, brincar, de certo modo, em vez de se opor à realidade, precisa dela para existir, já que

a criança repete nas brincadeiras as impressões que acabou de viver. Reproduz, imita. Para as menores, a imitação é a regra da brincadeira. A única acessível a elas enquanto não puderem ir além do modelo concreto, vivo, para ter acesso à instrução abstrata ... [A imitação] dirige-se aos seres que têm sobre ela [a criança] mais prestígio, aqueles que interessam a seus sentimentos (Wallon, 2007, p. 67).

Wallon traz ainda importantes aspectos que caracterizariam a brincadeira, fornecendo pistas para reflexões em torno de sua relação com as práticas educacionais. De acordo com seu ponto de vista, o "brincar" se caracterizaria por seu estilo "não sério" e por ser um espaço de distração e descanso, diferenciando-se, assim, do trabalho.

Sobre essa característica da brincadeira, Wallon (2007, p. 59) declara que

o brincar é sem dúvida uma infração às disciplinas ou às tarefas que impõem a todo homem as necessidades práticas de sua existência. ... Mas longe de ser sua negação ou renúncia, ele [o brincar] as pressupõe ... Só há brincadeira se houver satisfação de subtrair momentaneamente o exercício de uma função às restrições ou limitações que [a criança] sofre normalmente de atividades de certa forma mais responsáveis.

Portanto, para Wallon (2007), a brincadeira também se caracterizaria por sua "gratuidade" e "inutilidade", uma vez que constituiria uma atividade com motivação interna e finalidade em si mesma.

Semelhante ao que assinala Vygotsky, o brincar sob a ótica de Wallon supõe regras, sem as quais logo se esvairia em repetições monótonas e fastidiosas. Outro traço marcante do brincar, segundo Wallon, seria o acaso ou a incerteza quanto aos resultados. Nas palavras do autor, esse traço seria nada menos que "o antídoto do destino cotidiano" (Wallon, 2007, p. 66). A partir de tais questões, torna-se premente, pois, explicitar pontos de tensão na

\footnotetext{
1 Embora tenham pontos em comum, há que se destacar também diferenças entre as discussões da psicologia histórico-cultural e as da psicogênese walloniana em torno do brincar. Como ilustrativo dessas diferenças, Wallon não se detém no jogo protagonizado, elencando quatro diferentes tipos ou etapas do brincar, quais sejam: brincadeiras funcionais, que correspondem aos movimentos simples, como tocar objetos, estender os braços, emitir sons etc.; brincadeiras de faz de conta, como brincar de bonecas ou de "polícia e ladrão"; Brincadeiras de aquisição, na qual a "criança fica toda olhos e toda ouvidos [...] esforça-se para perceber e compreender: coisas e seres, cenas, imagens, relatos, canções parecem captar toda a sua atenção" (Wallon, 2007, p. 55); Brincadeiras de fabricação, que se caracteriza por juntar, combinar e modificar objetos.
} 
medida em que o campo educacional, valendo-se da importância da brincadeira para o desenvolvimento, busca capturá-la como instrumento pedagógico.

Com base nesses traços fundamentais da brincadeira, Brougère $(1995$; 1998) e Wallon (2007), cada um a seu modo, deixam claro que, ao se tentar fazer dela um meio para que determinado fim seja atingido, tal qual muitas vezes ocorre na escola, pode-se incorrer na sua descaracterização. Outros aspectos interessantes acerca da brincadeira e suas articulações com a educação podem ser encontrados na perspectiva socioantropológica de Brougere (1998). Nela, diferentemente do que se observa em Vygotsky, Elkonin e Wallon, há distinção entre jogo e brincadeira, uma vez que esta se configuraria como uma atividade própria da criança, com ou sem o suporte de brinquedos, e o jogo corresponderia a um conjunto de regras.

Para Brougère (1995; 1998), do ponto de vista de quem brinca, um comportamento se configura como brincadeira a partir de certos parâmetros. 0 primeiro é que ela não se origina de nenhuma obrigação, a não ser daquela que é consentida livremente. Em segundo lugar, não parece buscar nenhum resultado além da própria realização da atividade. Outro ponto fulcral para a discussão aqui empreendida é que, sob um olhar socioantropológico, a brincadeira não é um campo de certezas, a despeito de, cada vez mais, admitir-se seu valor positivo no campo da educação da criança (Brougère, 1995). Como se pode perceber, então, apesar das diferenças de enfoque, há semelhanças entre as caracterizações apresentadas por Brougère e as que são traçadas pelos outros autores já trabalhados nesta seção.

É válido ressaltar, outrossim, que, ao invés de naturalizar uma positividade para a brincadeira, o autor indaga: que condições permitiram atribuir um valor naturalmente positivo à brincadeira na educação da criança? Em resposta a essa indagação, Brougère (1995) afirma que tal discurso tem duas origens: uma que ele denomina "ideológica" e outra por ele designada como "científica".

Quanto à "origem ideológica", o autor destaca as mudanças na concepção de infância e de brincadeira no início do século XIX, devido ao que ele chama de "ruptura romântica". Segundo seu argumento, até então a brincadeira era considerada fútil ou nefasta, já que não se dava valor às atividades espontâneas da criança. Contudo, as ideias de Rousseau acarretaram mudanças na imagem da infância, já que exaltaram os comportamentos naturais da criança, e que expressariam sua verdade essencial. Diante dessa valorização da espontaneidade, a brincadeira também ganhará destaque como comportamento por excelência da criança.

No que concerne à "origem científica" do discurso de valorização da brincadeira na educação, Brougere (1998) frisa um traço dos primeiros discursos científicos que justificam o valor educativo da brincadeira, tal como o de Groos, um dos pioneiros no assunto. Para Groos (citado por Brougere, 1998), ela teria um papel biológico fundamental, pois seria um elemento da seleção natural, isto é, um treinamento dos instintos que melhoraria o desenvolvimento do adulto. Por conseguinte, pode-se depreender que, considerando tais origens do encontro entre "brincadeira" e "educação", segundo Brougere, a valorização educativa da brincadeira apoiou-se, a princípio, na supressão da dimensão social da educação da criança. 0 destaque à brincadeira como um meio educativo surgiu, pois, fundamentado ideológica e cientificamente em uma premissa bastante questionável nos dias atuais: a da naturalização da infância.

Sobre a tensa relação entre brincadeira e educação, Brougere (1995) se pergunta: quais, então, as possibilidades da brincadeira? Quanto a isso, o autor argumenta que não se pode fundamentar na brincadeira um programa pedagógico preciso, visto que dentre as marcas da brincadeira estão a gratuidade e a incerteza de seus resultados. Eis, então, o grande paradoxo desse "encontro": ao mesmo tempo em que é um espaço de aprendizagem e desenvolvimento, não é possível assegurar aprendizagens e desenvolvimentos na brincadeira.

Feita tal discussão, faz-se possível pensarmos sobre o processo de "instrumentalização" do lúdico a partir da Modernidade. Para tanto, procuraremos relacionar esse processo com o aprimoramento das tecnologias de biopoder.

\section{Instrumentalização do lúdico: dispositivo de disciplina e controle da infância?}

Como complexação dos jogos de poder ligados à invenção e institucionalização da infância e da "vontade de verdade", relacionada à construção de saberes que vêm se detendo sobre a criança, Lemos (2007, p. 80), a partir da inspiração genealógica 
foucaultiana, traz uma interessante cartografia das práticas atuais em relação à infância:

... passamos a definir o que é ser criança, o que uma criança em tal e tal idade faz, o que pensa e como pensa, o que deve sentir, como deve se alimentar e se vestir, quais são os cuidados necessários para a promoção de seu desenvolvimento integral, enfim, produzimos uma cartilha detalhada a ser seguida por todos os responsáveis pelo desenvolvimento das crianças.

Por conseguinte, não é por acaso a preocupação crescente de instituições, profissionais, familiares e especialistas com a forma como as crianças brincam e jogam, na tentativa de se apropriar dessas atividades a fim de direcioná-las "em favor" das diversas finalidades educacionais e mercantis.

Em razão disso, Brougere $(1995 ; 1998)$ aponta que o "encontro" entre brincadeira e educação vem fazendo com que a brincadeira passe a ser compreendida e usada cada vez mais como um "artifício", uma atividade de aprendizagem controlada pelo adulto/educador, que se vale da brincadeira para "seduzir" e "estimular" a criança à aprendizagem de determinados conteúdos didáticos. Nesse viés pedagogizante que instrumentaliza a brincadeira, a criança, em muitas circunstâncias, não toma iniciativa da atividade, tampouco controla seu curso. Por isso, Brougere (1998), considerando as características distintivas da brincadeira, é enfático ao advogar que, nesses casos, só existe brincadeira por analogia, já que a atividade não está atravessada pela gratuidade, pela futilidade, pela aleatoriedade, pela frivolidade e pela negociação de regras e sentidos por parte dos próprios participantes.

Assim, essas reflexões levam ao seguinte questionamento: o que esse afã de controle da atividade lúdica da criança na escola pode indicar acerca dos modos de subjetivação no campo educacional?

A hipótese aqui levantada, seguindo a linha defendida por Lemos (2007), é de que, em muitas situações, tais tentativas evidenciam a aliança entre mecanismos disciplinares e biopolíticos que visam regular a infância. A propósito, Lemos (2007, p. 78) ressalta que a apropriação do brincar, sob o discurso de que ele é um promotor de desenvolvimento, transforma-o, muitas vezes, num dispositivo de normalização e controle das condutas infantis, "a partir dos imperativos da sociedade capitalista, demandando, cada vez mais cedo iniciativas de estimulação cognitiva, visando inserir as crianças rapidamente na lógica de produtividade e submissão política". Prova disso é que, na educação infantil, o brincar da criança, apesar de ser uma de suas atividades principais, sofre um rigoroso controle do tempo e do espaço, já que só é espontâneo em ocasiões bem específicas, como nos momentos e locais de "recreação".

Nesse sentido, o "lúdico", no espaço institucional da escola, acaba sendo convertido em mais um "instrumento" pedagógico (Brougere, 1995; 1998). Passa-se, em razão disso, a tentar controlar o lúdico sob o argumento de que, assim controlado, dirigido, ordenado, vigiado, examinado, localizado em espaços definidos, como brinquedotecas, playgrounds etc., ampliar-se-ia seu potencial de promover o desenvolvimento da criança, numa apropriação, por vezes, questionável das teorias de Vygotsky e Wallon, por exemplo. Essa argumentação sustenta também um campo fortemente utilizado pelo mercado de consumo, que investe na fabricação de brinquedos e "jogos educativos ou pedagógicos". Tais instrumentos, pelos seus propósitos predefinidos e direcionados a fins específicos, funcionam como dispositivos reguladores do brincar da criança.

Para arrematar o prisma argumentativo ora exposto, vale, mais uma vez, destacar situações que clarificam essa articulação entre pedagogização da brincadeira e biopoder, numa aliança entre poder disciplinar e biopolítica. Nessa direção, as palavras de Lemos (2007, p. 85) são bastante elucidativas ao afirmar o controle sobre a brincadeira a partir de

como as crianças brincam, quando, com quem, com quais instrumentos, em que idade passou a ser matéria de interesse dos pais, dos educadores, de psicólogos, de médicos, de agentes de organismos de proteção social. Um olhar examinador observa incessantemente as crianças em suas brincadeiras. Os menores desvios frente ao esperado como normal, em cada fase do desenvolvimento, podem acionar mecanismos de atendimentos vários: com neurologistas, psiquiatras, psicólogos, professores de educação física e psicopedagogos.

Por conseguinte, a discussão aqui estabelecida permite-nos finalizar tal seção endossando o ponto de vista de que as crescentes tentativas de apropriação do lúdico como um recurso pedagógico na escola, a serviço da apreensão de conteúdos por parte da criança, podem estar articuladas ao aprimoramento de dispositivos de disciplinamento das crianças e regulação da infância. 


\section{Considerações finais}

A apropriação do lúdico pelo currículo escolar, na condição de atividade didática, isto é, como mais um recurso metodológico dentre as diversas atividades propostas pelo professor, com objetivos preestabelecidos de forma a oportunizar o cumprimento de metas previamente erigidas, pode ter ajudado a promover a cristalização do lúdico, que, dessa forma, corre o risco de perder potência inventiva. Desse modo, estabelece-se a seguinte tensão entre escola e atividade lúdica, assim como conceituada pela literatura apresentada nesse artigo: "se o lúdico carrega como característica a gratuidade..., como falar de um lúdico que carrega consigo um material educativo e um objetivo a ser alcançado para todos aqueles que brincam?" (Pinto, 2010, p. 45).

Essa questão, pois, alude ao embate, exposto nas seções anteriores, entre diferentes lógicas de ação na escola em torno da atividade lúdica. A tensão entre diferentes lógicas de ação a esse respeito, entendidas aqui como "nós" de significação das atividades escolares, evidencia, portanto, que a escola é formada por diferentes fios discursivos e modos de fazer, resultantes de linhas de força distintas que atravessam o seu cotidiano (Sarmento, 1998).

De maneira articulada com essa questão, a discussão trazida neste artigo pôs em causa a apropriação pedagogizante e instrumentalizadora do brincar como dispositivo de disciplina, normalização e controle da infância, lógica de ação que vem se tornando cada vez mais forte no contexto da instituição escolar. Como se tentou mostrar, tal fato não se dá por acaso, mas no momento em que se articula intimamente com a própria invenção e institucionalização da infância na Modernidade e com o surgimento de novas modalidades de poder, as quais, a partir do início daquele período, ocuparam-se da vida, incidindo, simultânea e complementarmente, no corpo-organismo e no corpo-espécie.

Apesar disso, com essas colocações, não pretendemos endossar previsões pessimistas no que concerne às implicações políticas da educação na contemporaneidade. Pelo contrário, inclusive por entendermos a escola como um espaço multirreferenciado, temos em conta que as possibilidades de agenciamento de processos de subjetivação pela educação e pela escola estão sempre em aberto, mesmo porque, de acordo com o ponto de vista foucaultiano, a resistência ao biopoder se encontra em seu próprio objeto: a vida. Sobre isso, relações de poder pressupõem sempre possibilidades de resistência e de linhas de fuga.

A título de reforço desse argumento, para Foucault (2010, p. 289), poder e liberdade não se opõem, mas se relacionam complexamente, sendo um condição do outro:

O poder só se exerce sobre "sujeitos livres" - entende-se por isso sujeitos individuais ou coletivos que têm diante de si um campo de possibilidades em que diversas condutas, diversas reações e diversos modos de comportamento podem acontecer. Não há relações de poder onde as determinações estão saturadas - a escravidão não é uma relação de poder, pois o homem está acorrentado (trata-se então de uma relação física de coação) - mas apenas quando ele pode se deslocar e, no limite, escapar.

Assim sendo, há que se investir nas possibilidades de que a educação e a escola fomentem cada vez mais resistências à constituição de identidades e de maneiras de viver, agir, sentir e pensar sujeitadas, regulamentadas e controladas. No caso da temática específica deste trabalho, há que se apostar em perspectivas que compreendam o lúdico como uma possibilidade de experimentação e inventividade, capaz, portanto, de criação de relações alteritárias.

\section{Referências}

Brougère, G. (1995). Brinquedo e cultura. São Paulo: Cortez.

Brougère, G. (1998). Jogo e educação. Porto Alegre: Artes Médicas.

Bujes, M. I. E. (2002). Infância e maquinarias. Rio de Janeiro: DP\&A.

Elkonin, D. B. (1998). Psicologia do jogo. São Paulo: Martins Fontes.

Foucault, M. (1979). Microfísica do poder. Rio de Janeiro: Graal.

Foucault, M. (1999). Em defesa da Sociedade. São Paulo: Martins Fontes.

Foucault, M. (2008a). Segurança, Território, População. São Paulo: Martins Fontes. 
Foucault, M. (2008b). Nascimento da biopolítica. São Paulo: Martins Fontes.

Foucault, M. (2005). Vigiar e Punir: História de violência nas prisões. Petrópolis: Vozes.

Foucault, M. (2010). 0 sujeito e o poder. In H. L. Dreyfus \& P. Rabinow. Michel Foucault, uma trajetória filosófica: Para além do estruturalismo e da hermenêutica. (pp. 273-295). Rio de Janeiro: Forense Universitária.

Gadelha, S. (2009). Biopolítica, governamentalidade $e$ educação: Introdução e conexões a partir de Michel Foucault. Belo Horizonte: Autêntica.

Lemos, F. C. S. (2007). A apropriação do brincar como instrumento de disciplina e controle das crianças. Estudos e Pesquisas em Psicologia, 7(1), 78-88.

Marx, K. (1978). Manuscritos econômico-filosóficos e outros textos escolhidos. São Paulo: Abril Cultural. (Coleção Os pensadores).

Pagni, P. A. (2010). Infância, arte de governo pedagógica e cuidado de si. Revista Educação e Realidade, 35(3), 99-123.

Pinto, G. A. T. (2009). Sentidos do lúdico na educação infantil: dos dispositivos institucionais aos modos de fazer. Tese de Doutorado, Programa de Pós-Graduação em Educação Brasileira da Universidade Federal do Ceará, Fortaleza.
Sarmento, M. J. (1998). Lógicas de acção nas escolas. Lisboa: Fundação Mário Soares e Gradiva.

Sarmento, M. J. (2004). As culturas da infância nas encruzilhadas da segunda modernidade. In M. J. Sarmento \& A. B. Cerisara. (Ed.). Crianças e Miúdos: Perspectivas sociopedagógicas da infância e educação. (pp. 9-34). Porto: Asa Editores.

Vygotsky, L. S. (1995). Obras escogidas. (Tomo III). Madrid: Visor.

Vygotsky, L. S. (2001). A construção do pensamento e da linguagem. São Paulo: Martins Fontes.

Vygotsky, L. S. (2007). A formação social da mente. São Paulo: Martins Fontes.

Wallon, H. (2007). A evolução psicológica da criança. São Paulo: Martins Fontes.

Wertsch, J. V., \& Smolka, A. L. B. (1995). Continuando o diálogo: Vygotsky, Bakhtin e Lotman. In H. Daniels (Ed.). Vygotsky em foco: Pressupostos e desdobramentos. (pp. 121-150). Campinas: Papirus. 